\title{
Fiscal decentralisation frameworks for Agenda 2030: understanding key issues and crafting strategic reforms
}

\section{Commonwealth Journal of Local Governance \\ Issue 20: December 2017 \\ http://epress.lib.uts.edu.au/ojs/index.php/cjlg}

\author{
Paul Smoke \\ Wagner Graduate School of Public Service \\ New York University \\ United States of America \\ Email: paul.smoke@nyu.edu
}

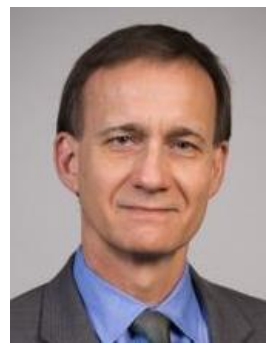

\begin{abstract}
Local and regional governments (LGS) will be important actors in ensuring that the UN's Sustainable Development Goals (SDGs) are translated into action that is tailored to the most pressing needs of their communities. Despite broad recognition of the subnational dimension of the SDGs, the specific roles that LRGs can and should play and the capacities and resources they require have received insufficient official consideration to date. If LRGs are to maximise their developmental impact, countries require robust intergovernmental frameworks and policies that empower, finance, motivate and support local and regional governments and citizens. The paper examines the requirements and options for subnational government finance and provides suggestions for strategic implementation, concluding by linking fiscal decentralisation reforms to the SDGs.
\end{abstract}

\section{Subnational governments and the SDGs: key roles and challenges}

The Agenda 2030 commits the international community to achieving an ambitious set of Sustainable Development Goals (SDGs) in little over a decade (UNDESA Division for Sustainable Development 2015). If this is to occur, countries will need to work in new ways and with new partners, and they must effectively use the governance, fiscal and managerial mechanisms at their disposal. Local and regional governments (LRGs) will be important actors in ensuring that the SDGs are translated into action that is tailored to the most pressing needs of their communities. They will also need to catalyse local expertise and resources, as well as secure support from domestic and external sources, to support this demanding agenda. 
The UN Secretary General's Synthesis Report on the SDGs states "many of the investments to achieve the sustainable development goals will take place at the subnational level and be led by local authorities" (UN General Assembly 2014, p. 22, para. 94). The High Level Panel on the Post-2015 agenda claims that the battle for sustainable development will be lost or won in cities. The New Urban Agenda (from Habitat III) calls for "a new model of urban development...to integrate all facets of sustainable development to promote equity, welfare and shared prosperity" (UN-Habitat, Habitat III Secretariat 2016). The Addis Abba Action Agenda on Financing for Development (FfD) highlights the subnational role in financing development and commits to scaling up international cooperation to support LRGs (UNDESA, Financing for Development Office 2015, p. 16, para. 34).

Despite broad recognition of the subnational dimension of the SDGs, the specific roles that LRGs can and should play and the capacities and resources they require have received insufficient official consideration to date. To ground the rationale for Commonwealth countries to take action, it is useful to recall some of the main reasons why LRGs need to be key players in sustainable development. ${ }^{1}$

- First, high-income countries - and increasingly low- and middle-income countries - expect LRGs to perform a range of public functions. In most Commonwealth countries LRGs are responsible for local planning and regulation, a range of public services and infrastructure investment and maintenance, among others. LRGs account for about a third of public spending and 50\% (or more) of public investment in high-income countries (see UCLG 2010; Frank and Martinez-Vazquez 2016; OECD and UCLG 2016). Fiscal decentralisation is more recent and uneven in many low-income countries - LRGs often account for $10 \%$ or less of public spending, although the share is substantially higher in some cases, such as Kenya and South Africa.

- Second, many countries suffer from large gaps in public services and basic infrastructure critical for sustainable development. Needs are expected to surge as population growth and urbanisation advance (UCLG 2010, 2014; Ingram et al. 2013; UN General Assembly 2014, UNDESA 2017). The number of urban dwellers in the Commonwealth is projected to grow from 879 million today to 1.3 billion by 2030, with the highest growth in India, Nigeria, Pakistan and Bangladesh (UN-Habitat 2016). Filling the gaps will demand robust planning and investment, much of it related to functions that LRGs do or could play a key role in delivering and financing. Evidence indicates that LRGs can contribute significantly to development by raising resources, making public investments, and managing service delivery and other functions, advancing both local and national goals. ${ }^{2}$

\footnotetext{
${ }^{1}$ See a more detailed discussion in UCLG (2015).

${ }^{2}$ Evidence is reviewed in Local Development International (2013) and European Commission (EC) (2016).
} 
- Third, many SDGs include multiple components that must be addressed collectively in specific jurisdictions, as embodied in SDG 11. Given their proximity to local residents, LRGs have more potential and motivation than national actors to think holistically about integrated territorial development, as highlighted by the Commonwealth Local Government Forum (CLGF) and others (CLGF 2007, 2013; Romeo 2011; EC 2016). In addition, while SDG 11 is the only SDG that specifically targets LRGs, 103 of the 169 SDG targets (61\%) are considered relevant to cities or have a component and will need action at the local level (Greene and Meixell 2017, p. 10). National actors need to elaborate frameworks and provide support, but LRGs can often take the lead role in developing and managing integrated sustainable development plans to inclusively meet the needs of their constituents.

- Fourth, many SDGs centre on alleviating prominent and interconnected global conditions that pose significant challenges to sustainable development - global warming, financial instability, energy deficiencies, health crises, and food insecurity, among others. International and national government measures are clearly essential, but LRGs have already taken action on these fronts in some countries and are well situated to develop additional innovative responses - through climate adaptation policies, energy conservation, green growth strategies, and local resource mobilisation, among others (see, for example, UCLG 2014).

All LRGs can help advance the SDGs, but urban areas are especially prominent. Cities drive economic growth - urban areas commonly produce a quarter or more of GDP in both high-income countries and low- and middle-income countries. Nearly half of the global population is already urban, and urbanisation is expected to near $85 \%$ in industrialised countries and $64 \%$ in developing countries by 2050 (see, for example, UNDESA Division for Sustainable Development 2015). The urban record in creating jobs, delivering services and promoting sustainability, however, is uneven, and low-income countries face acutely severe challenges (see, for example, McGranahan and Satterthwaite 2014). To achieve Agenda 2030 cities will need to be able to take a lead in ensuring equitable economic growth, planning for resilience and climate adaptation, and encouraging innovation and social integration.

If LRGs are to maximise their developmental impact, countries require robust intergovernmental frameworks and policies that empower, finance, motivate and support LRGs and citizens. Current systems, even in high-income countries, exhibit weaknesses or need updating, and capacity deficits can be large, especially in low-income countries. Particularly striking are limitations on the revenue side - own-source revenues, intergovernmental transfers, and development finance - and unfunded expenditure mandates are not uncommon.

Much has been written and considerable action taken to improve fiscal decentralisation (Bahl et al. 2013; UN-Habitat 2015). Some reforms have helped, but many fall short, especially in low- and middle-income countries. Weaker than expected performance results from various factors - 
inadequately contextualised design, unrealistic expectations, haphazard implementation, and political forces, including central reluctance to empower LRGs and local political dynamics. Conventional approaches to fiscal decentralisation are useful, but their application - and their relevance for the SDGs - must recognise the challenges to be overcome and the extensive variations in goals, structures, functions, capacities and performance across and within countries. ${ }^{3}$

Many considerations are relevant for defining and realising a stronger LRG role in the SDGs. This article focuses on four.

- First, decentralisation reforms are often unduly standardised and inadequately coordinated more contextually sensitive and holistic reforms could enhance synergies among intergovernmental system elements and improve results.

- Second, efforts to improve LRG finance are often inadequate and piecemeal - greater focus on integrated resourcing can support development and the SDGs.

- Third, despite the value of a more holistic and integrated approach to framing reform, not everything can be done at once - crafting a pragmatic implementation strategy is essential for even the best designed reforms.

- Finally, the prominence of the SDGs raises a productive opening to rethink fiscal decentralisation reforms that have not gained traction on their own merit.

\section{Contextually grounding and integrating decentralisation reforms}

Reforms to improve intergovernmental systems and enhance the role and performance of LRGs are common, but they are often based on simplified general principles. These can lead to overly homogeneous reforms and do not provide LRGs with flexible tools to address their distinct development needs (see Bahl et al. 2013 and Smoke 2015a). In addition, many reforms target specific elements of the system - for example by focusing on either the expenditure or revenue side, only addressing policy design or implementation and management, etc. A principle-driven and targeted approach is pragmatic, but reforms must also account for specific characteristics of each country and LRG, and even narrow reforms must be structured to work harmoniously within the larger intergovernmental system.

Decentralisation is framed as assigning public functions to LRGs along with systems and funds to support implementing these responsibilities to meet public goals. ${ }^{4}$ Its multiple forms and accountability channels are well known - deconcentration (local units of higher levels), devolution (elected LRGs with semi-autonomous powers) and delegation (certain function(s) contracted to a LRG or private entity) - as are the key dimensions: administrative, fiscal and political. These dimensions cannot be treated independently if decentralisation benefits are to be achieved, e.g.

\footnotetext{
${ }^{3}$ Diversity is a theme throughout the decentralisation literature. See UCLG $(2010,2014)$.

${ }^{4}$ Overviews include CLGF (2007), Boex and Yilmaz (2010) and Eaton et al. (2011).
} 
political decentralisation (elections) means little unless LRGs have the resources and capacity to respond to their constituents. Decentralisation can be undertaken in unitary systems (central government defines LRG powers), or in federal systems (an intermediate tier - state or province - has a role in defining/managing functions of lower tiers). Unitary systems can be used to govern very large countries or small island states. Exactly how the public sector will operate depends on the types of powers decentralised and the position of LRGs in the larger institutional architecture.

LRG service provision - especially under devolution where citizens directly elect councils - is expected to improve delivery through better governance. Increased proximity of decision makers to their constituents increases accountability and responsiveness, and a more precise tailoring of actions to local needs increases efficiency in the use of limited funds. Relative to central actors, LRGs in principle have greater incentives to innovate (and compete with peers). LRGs can also think holistically about local development compared to specialised sectoral agencies working in silos, which often dominate at central level. Nevertheless, inadequate systems, undue central interference, problematic local politics and weak capacity can work against potential benefits of decentralisation.

Fiscal decentralisation starts with the division of public functions, both those unique to LRGs and those shared with other levels. LRGs are typically given legal authority over a set of functions, but murky legal provisions or obstructionist central behaviour can hinder implementation. Ambiguity can create gaps or redundancies in service delivery, complicate resource mobilisation and allocation as well as create uncertainty about what central governments and citizens should hold LRGs accountable for.

There have been recent efforts to promote a broader view of decentralisation that advocates empowering LRGs to meet a general mandate to develop and provide for the welfare of their territories rather than simply to assume roles and functions assigned to them by the central government (CLGF 2013; Romeo 2011; EC 2016). Often referred to as developmental local government, such an approach sees LRGs as proactive drivers of integrated development, which reinforces their role in supporting the SDGs. This way of operating, however, places greater demands on LRGs.

As per the 'finance follows function' principle, each level needs adequate funding to meet its obligations and general development mandate, which is often a challenge (more below). Effective fiscal decentralisation also depends on systems to manage generation and expenditure of LRG resources, including public financial management (PFM) and fiscal responsibility frameworks. Much effort has been devoted to developing such mechanisms, including use of new technologies for assembling and using information. 
LRG performance also depends on the definition, implementation and enforcement of the broader constitutional, legal and administrative framework in which LRGs operate. This goes beyond fiscal and managerial dimensions that focus on LRG powers and functions, planning and budgeting, etc. Property rights, for example, affect property tax policy and administration and have implications for governance and accountability. Civil society rights open space for civic engagement, which can influence LRGs behaviour and the types of partnerships and relations they develop with different sections of the community (Yilmaz et al. 2010; Agrawal and Ribot 2012; Faguet 2014). Such factors can have a significant effect on the extent to which LRGs are accountable to their constituents in how they generate and use public resources.

Finally, it is vital to highlight the significance of the institutional diversity noted above. Countries may have multiple levels that blend devolution, deconcentration, and delegation in varied ways. One form may dominate or the mix may vary, e.g. devolution at one level and deconcentration at another. Intermediate tiers (states, provinces) may have more power than lower tiers (municipalities, districts, etc.), especially in federal systems like Canada, India, Nigeria and Pakistan, or the opposite may be true, as in South Africa, Indonesia and the Philippines. Relations among levels may be relatively independent or more hierarchical, affecting accountability and the autonomy with which LRGs operate.

Relations among units at a particular level, including within key metropolitan areas, can range from well-coordinated to highly fragmented, shaping service delivery across multiple jurisdictions (Slack 2015). Other governmental (e.g. service delivery boards) and/or private actors may have specific responsibilities, and these may or may not be well linked to LRGs. In some cases, other actors trespass on the legally defined functional territory of LRGs.

Small island developing states (SIDS) face particular challenges in that they are often characterised by fragmented and weak administrations and governance structures, few sources of revenue, small populations, and in island atolls large distances between jurisdictions, limiting opportunities to take advantage of economies of scale (CLGF 2015). They also face significant impacts from climate change and have limited resilience to economic or environmental shocks. In such environments LRGs are on the front lines in terms of service delivery but have limited financial tools at their disposal, and the blurring of responsibilities between central and local administrations can add to the challenges.

In short, decentralisation and LRG performance must be understood in terms of the institutional framework in a specific country and the formal and informal relations among differentially empowered levels and units of government and other governmental and nongovernmental actors. Without such an understanding, it is not possible to fully explain LRG performance, to interpret properly the factors that shape it, or to develop meaningful and sustainable reforms intended to 
improve it. In some cases, major changes in institutional structures could be justified, but only a few countries (e.g. Kenya, Nepal and South Africa) have managed such politically sensitive restructuring.

\section{Requirements and options for subnational government finance}

Finance is critical for the SDGs, and subnational finance has been characterised as the missing link in sustainable development finance (UCLG 2015). Like decentralisation in general, there have been many efforts to improve LRG finance, but they have often been fragmented and performed unevenly (UCLG 2010; Bahl et al. 2013; Smoke 2015a; UCLG 2015; UN-Habitat 2015; UNDESA and UNCDF 2017). Various frameworks and analysts have targeted selected elements - functional assignment (particular sectors), local revenue generation (specific sources, such as property tax or user charges), intergovernmental transfers (specific types, such as unconditional, conditional or performance-based) and various forms of development finance (transfers, subsidised loans, market loans).

Dedicated policies and focused analyses are needed, but so is an understanding of how these elements interact. Are there adequate resources to finance a new LRG function? Might transfers discourage own-source revenue generation and borrowing even when use of these options is viable? Are some actions more fundamental or higher priorities or more feasible than others? On balance, it is important to consider reforms in a more integrated and strategic way, even though specific reforms ultimately require dedicated attention.

Options, starting points and trajectories will depend on current and evolving economic and fiscal conditions in each country, including the economic base, the level of development of capital markets and the availability and nature of international assistance in poorer countries. Thus, although promoting greater LRG financial capacity and autonomy is generally desirable, appropriate provisions in a particular country will vary, and they should be expected to change over time as relevant conditions evolve to promote stronger economic development and create better access to capital markets.

Another critical concern is that individual countries are comprised of a range of LRGs with different needs and capacities - ranging from metropolitan and secondary cities to small towns and rural areas - that require varying mixes of finance policies and instruments. Some LRGs (especially urban) have greater opportunities to raise resources, while in other cases, transfers will be more important. Similarly, in some countries at least a number of LRGs will be able to tap capital markets, while for others central government support of LRG borrowing and development finance more generally will be required.

The SDG/FfD agenda has focused on development finance, particularly borrowing and private finance for LRG investment. This is appropriate but not sufficient for LRGs to engage effectively in the 
SDGs. LRGs also need adequate authority over infrastructure development if they are to be responsible for it. They will be unable to take loans without managerial and fiscal capacity, including to raise revenues for operation and maintenance and debt service. The LRG development finance environment is especially challenging in many low- and middle-income countries. Thus, assessment of what is initially feasible and a strategy to build a sustainable LRG finance system - recurrent and capital - are essential.

\section{The revenue landscape}

Central governments have intrinsic advantages in revenue generation given the nature of productive revenue bases and administrative scale economies, while LRGs often have the edge in providing certain public services due to variations in needs and preferences across jurisdictions. This means that intergovernmental transfers are inevitably important to offset the typical revenue-expenditure imbalance, and how national resources are shared with LRGs is critical. Yet there is also a convincing case for LRGs to raise a reasonable portion of their funds. LRG revenue generation reduces pressure on national budgets, links the costs and benefits of services, raises funds to repay loans for infrastructure investment, and frees up national resources to assist LRGs with weaker fiscal capacity, among others.

\section{Own-source revenues}

The often high functional demands and restrictions on own-source revenues generation result in substantial differences between LRG expenditure responsibilities and revenue capacities. LRGs in middle-income and high-income countries may collect 20-30\% or more of their total revenue. In lowincome countries, it is often $10 \%$ or less, although there are outliers and there can be much variation within countries. Generally, the superior revenue bases and capacity of major urban governments relative to smaller urban and rural jurisdictions allows them more fiscal independence, but not always. In federal systems, urban governments' revenue authority can be constrained by state government control over local revenue policies and practices.

There is broad agreement that many central governments, especially in low- and middle-income countries, are cautious and decentralise fewer revenue sources than would be justified by fiscal principles and LRGs' needs (UCLG 2010, 2015). Still, a range of LRG own-source revenues is typically available (Bahl and Bird 2008; McCluskey and Franzen 2013; Martinez-Vazquez 2013; UNHabitat 2015. These include property tax, fees and charges, licences, economic activity taxes, and sometimes at intermediate, urban or metropolitan levels, motor vehicle and natural resource revenues and business or sales taxes. Voluntary LRG surcharges on higher-level taxes are commonly recommended but less frequently used, more commonly in federal or large countries and typically for regional rather than local governments. 
Even where LRG revenues are used, however, they are often underutilised. Transfers can create disincentives for LRG revenue generation, limited information and capacity create administrative challenges, and local political dynamics can weaken enforcement. Central regulations and controls are also a common constraint. Full local autonomy over any tax is rare, but there can be some control over the rate, at least within a range. Charges for LRG services, such as water, may be subject to regulation but with some discretion. Of course, LRG own-source revenues and tax sharing provisions are quite diverse, as are the conditions in which they operate. Thus, if LRG revenues are underutilised, it is important to understand what limits yields if the situation is to be improved.

In several countries, there have been positive LRG revenue generation reforms. Some initiatives involve fresh approaches to managing conventional LRGs sources, such as property taxes, including in Bogota (Colombia), Nairobi (Kenya), Mzuzu (Malawi), Maputo (Mozambique), Lagos (Nigeria), and Bo (Sierra Leone). There have also been initiatives to create and expand new LRG sources, such as land value capture (LVC) to raise funds from land value increments generated by infrastructure (roads, sewerage, transit, etc.) ${ }^{5}$ LVC instruments include betterment levies, land readjustment, special assessments, and tax increment financing, among others. Thus far LVC has been used more in highincome and stronger middle-income countries, e.g. Brazil, China, Columbia, and India, but there will be greater scope in low- and middle-income countries as urban growth advances and fiscal reforms to strengthen LRGs are adopted.

\section{Intergovernmental fiscal transfers}

LRGs in most countries - whether high-income countries or low- and middle-income countries significantly rely on intergovernmental fiscal transfers given the imbalance between appropriate expenditure and revenue decentralisation, although urban areas can be more fiscally independent. ${ }^{6}$ Transfers can improve LRG resource access and autonomy, as well as help to meet priority national development, service delivery and equity goals, including those embodied in the SDGs.

Several aspects of intergovernmental fiscal transfers systems merit consideration. First, given ownsource revenue constraints, LRGs require sufficient and predictable intergovernmental fiscal transfers. There are many demands for public revenues, so central governments cannot fully provide for all LRGs, and the centre also needs flexibility to respond to macroeconomic conditions. Nevertheless, there has been a movement to define the total volume (pool) of intergovernmental fiscal transfers resources in a relatively predictable way to limit disruptive (and politicised) variations in the amount of national funds shared with LRGs.

\footnotetext{
${ }^{5}$ Ingram and Hong (2012), World Economic Forum (2014), Suzuki et al. (2015), UN-HABITAT and IDB (2017), and UNDESA and UNCDF (2017) review various experiences with land value capture.

${ }^{6}$ Synthetic reviews of intergovernmental transfers include Bird and Smart (2002) and Shah (2013).
} 
Second, it is now common to allocate the intergovernmental fiscal pool on the basis of objective criteria, reducing politicisation and improving transparency. Intergovernmental fiscal formulas allow the centre to advance key goals - improving LRG resources (and targeting poor LRGs if intergovernmental fiscal transfers are redistributive), increasing autonomy (unconditional intergovernmental fiscal transfers), and targeting high priority functions, including those related to SDGs (conditional intergovernmental fiscal transfers). Indeed, a key decision about intergovernmental fiscal transfers systems is which goals are a priority and what this implies for how these transfers should be allocated.

Third, there can be problematic incentives generated by intergovernmental fiscal transfers. If transfers are large and the formula fails to incentivise LRG tax effort, intergovernmental fiscal transfers may dampen own-source revenues generation (and local accountability) as well as borrowing by creditworthy LRGs, even for self-financing infrastructure (reducing funds for less bankable LRGs or investments). In addition, strong conditionality may create incentives to over-privilege certain sectors or to invest in infrastructure that LRGs do not have resources to operate and maintain.

Despite some of the trends, the practice of intergovernmental fiscal transfers is highly diverse. Many countries increasingly define rules for determining the annual intergovernmental fiscal transfer pool, e.g. basing it on a share of a set of taxes or national revenues sources (e.g. Ghana, Kenya, Indonesia, Mexico, the Philippines). In other cases, the intergovernmental fiscal transfers pool is still determined annually in the budget process (e.g. South Africa, Uganda) or set for a specific period of time (e.g. five years in India and Pakistan based on National Finance Commission recommendations).

Some countries have relatively consolidated intergovernmental fiscal transfers systems, e.g. one main unconditional formula-based intergovernmental fiscal transfers in Indonesia, Kenya, and South Africa. Other cases use more than one intergovernmental fiscal transfers or place conditions on general revenue sharing use, as in Brazil, Ghana and Uganda. The level of conditionality can shift over time, as in Uganda, where the centre has increased restrictions on the use of shared funds. Many countries share national revenue with each level of government, but in many federal countries, such as Canada, India, Nigeria, and Pakistan, most transfers go to the intermediate tier, leaving sharing with lower levels largely a state or provincial decision. In all countries a key concern is getting the right balance among the various types of transfers and creating incentives for LRGs to behave in a developmental and fiscally responsible manner. 


\section{Financing development}

Subnational governments account globally for nearly two-thirds of public infrastructure investment, about a third of which is financed with grants. ${ }^{7}$ In low-income and many middle-income countries, grants tend to dominate. In some cases, a main general transfer programme covers recurrent and capital spending, while in others there are dedicated development transfers, some unconditional, but more commonly for specific sectors. These may be distributed for specific projects or by formula, and LRG matching contributions are not uncommon.

Access to loans from capital markets has been important in high-income countries, but in low- and middle-income countries this is an option primarily for selected larger cities, metropolitan governments and regions. Developing LRG borrowing channels can be achieved over time, but this requires reforms to strengthen the intergovernmental fiscal framework and to build LRG fiscal responsibility and creditworthiness. Where direct access to capital markets is not feasible, quasipublic financial intermediaries, such as municipal development banks/funds have been used. Many such entities have performed poorly, but often due to design flaws and politicisation that can be corrected where there is a genuine desire for reform.

There have in fact been efforts to improve LRG access to development finance. Some countries have developed new borrowing/fiscal responsibility frameworks and have been reinventing financial intermediaries for LRG lending that are more professional and operate on more market-based principles, as well as opening financial markets directly to eligible LRGs (see Ingram et al. 2013; Smoke 2013; UCLG 2015). Other approaches to enhance LRG access to loans include, for example, risk mitigation strategies, such as central government credit guarantees, co-financing initiatives, secondary market support, bond banks and credit pooling (see Kehew et al. 2005; Matsukawa and Habeck 2007; FMDV 2015; AFD and UNDP 2016). A key element of reform, especially for secondary and smaller cities, is building the capacity of administrations to access capital markets and manage loans once secured.

Low- and middle-income countries that have made progress in LRG borrowing have typically offered a range of options using different approaches and with different target LRGs and types of projects. India has expanded use of municipal bonds (with and without tax-free status and guarantees). Other mechanisms at the state level, such as Tamil Nadu Urban Development Fund and Greater Bengaluru Water Supply and Sewerage Project, use pooled financing for LRG lending. Much infrastructure in the Philippines is financed through a public entity, the Municipal Development Fund (which mixes grants and loans) and a private entity, the Local Government Unit Guarantee Corporation. The Development Bank of Southern Africa (a government-owned entity) and the Infrastructure Finance Corporation (a

\footnotetext{
${ }^{7}$ See the analysis in Martinez-Vazquez and Timofeev (2012). Other studies indicate a smaller but still major role.
} 
private corporation that issues bonds) are the largest players in LRG lending in South Africa, but some larger metropolitan governments, such as Cape Town and Johannesburg, have issued bonds.

Although these examples have pursued approaches that offer multiple options, there are also country reforms that largely focus on particular mechanisms. LRG infrastructure finance in Sri Lanka, for example, is supported through the Local Loans and Development Fund (LLDF), which provides funds at concessional rates for public utilities. Belize City (Belize) has issued municipal bonds for public investments, showing that this instrument can be viable under the right conditions even for small cities.

In short, advances are possible, but the majority of LRGs in many low- and middle-income countries are not creditworthy and need support to build capacity, develop financing strategies and access finance. A good development system under such conditions requires an appropriate range of debt finance options, ranging from grants and subsidised (according to clearly specified criteria) loans for poorer LRGs and non-self-financing projects, to various types of loans for more fiscally sound LRGs and revenuegenerating projects.

Direct access to capital markets is appropriate for creditworthy LRGs if the central government regulates borrowing and enforces fiscal responsibility. Where LRGs are fiscally weaker, more public intervention is generally required. Dedicated financial intermediaries can initially be publicly controlled if designed to minimise politicisation of lending and repayment. Over time, the private sector can become increasingly engaged as LRG creditworthiness improves and perceptions of risk abate.

The most critical challenge is how to 'graduate' weaker LRGs from grants and subsidised loans to greater use of credit markets. This requires some harmonisation in the use of grant and loan mechanisms. Wealthy urban governments should not receive grants and highly subsidised loans for self-financing projects - such funds should largely be reserved for weaker LRGs and projects that cannot directly recover costs. Weaker LRGs could be required to take modest loans to begin to build capacity and a path towards creditworthiness. Another issue is how to capitalise municipal development banks/funds, which might be achieved through an evolving mix of support from development partners and private sources.

Other mechanisms and approaches can also enhance infrastructure finance. LRG public-private partnerships (PPPs) have been challenging, especially in low- and middle-income countries, but they hold future promise (see Marin 2009; Brinkerhoff and Brinkerhoff 2011; Ingram et al. 2013; Suzuki et al. 2015). A number of development partners, including the IFC, the African Development Bank and the multi-donor Cities Development Initiative for Asia and UNCDF, have supported or proposed various kinds of Project Preparation Facilities (PPFs) to promote local infrastructure investment. ${ }^{8}$

\footnotetext{
${ }^{8}$ GIZ (2014) and World Economic Forum (2014) review some experiences with project preparation facilities.
} 
Concerns about PPFs include their focus on bankable large-scale projects and favouritism to the private sector over LRGs, but they may free up public funds for LRGs and potentially be modified for direct LRG use.

\section{Strategic implementation ${ }^{9}$}

The types of reforms needed to expand or recalibrate intergovernmental and LRG finance systems to better support the SDGs will vary across countries. High-income countries with more established systems and capacities should be in a better position to adopt reforms. In many low- and middleincome countries where decentralisation is newer and capacity needs to be developed as reforms are rolled out, the challenges tend to be greater. What needs to be done may be some distance from current policies and practices on the ground. Moving too quickly or without careful planning may jeopardise reform initiatives and limit their intended results.

The first step is obviously to document the specific nature of the problem(s) to be addressed. Are LRG services or revenues generally lacking or is the problem more specific? The next step is understanding why the problem exists. Is the source primarily technical, political or both? Is the problem more related to empowerment or capacity deficits? Have LRGs failed to meet responsibilities or are other actors obstructing their performance or intruding on LRG roles? If resources are limited, what are the key issues - weak LRG creditworthiness, flaws with intergovernmental transfer systems, failure of LRGs to collect revenues from a productive base, local citizen reluctance to pay taxes or user fees, and so on? Further assessment is also required. Are LRGs not creditworthy because they do not have access to own-source revenues or they have weak capacity or they have political credibility problems and cannot collect potentially productive revenues?

It is impossible to exhaustively outline the needed analysis here - there could be many more questions, and a serious analysis would have to dig deeper. But developing a sense of answers to some basic questions can begin to suggest the types of additional inquiry required and to identify solutions that might be considered. At the same time, the relative severity of underlying problems and linkages among them need to be documented, at least to the extent that some operationally specific steps can be proposed that do more than adopt generic reforms routinely recommended to deal with typical problems.

Different actions will involve different lead actors. For example, only the central government can deal with a lack of LRG empowerment or intrusion of central agencies in LRG responsibilities. LRGs, however, may be in a position to improve collection of own-source revenues or pursue new sources

\footnotetext{
${ }^{9}$ Work on implementation of decentralisation and LRG reform includes: Connerley et al. (2010), Eaton et al. (2011) and Smoke (2015b).
} 
consistent with legal provisions. In many cases, collaborative actions by central and subnational governments will be required.

Once the nature of a problem has been identified and the factors underlying it have been documented, a pragmatic strategy for reform can be developed. This is potentially demanding, and there are many ways it could be done, again depending on context and which actor leads. If action were taken by the central government to enhance the powers and capacity of LRGs, for example, a strategy might include certain elements - starting points, incentives, and capacity development.

First, it would be important to identify starting points for the reform process. In some cases, there will be opportunities to take major steps quickly. In other cases, a more cautious approach would be indicated. Taking into account the results of the type of diagnostics suggested above, initial steps could engage motivated partners and focus on solutions more likely to realise quick wins. This requires prioritising reforms, perhaps focusing on basic tasks that do not excessively intimidate key power bases or overpower LRG capacity. It would of course be productive to identify something that is significant and visible enough to begin to move the system in a better direction and with potential to initiate a process that could sustain advances. Leadership from both central and local and regional governments in this phase of reforms is essential in building a shared vision and stakeholder buy-in for the starting point and more challenging steps to come.

A related concern is that national decentralisation reforms often assume LRGs to be similar and do not sufficiently distinguish among them. Treating those with limited capacity as being capable of assuming major functions tempts failure, while unduly controlling LRGs with demonstrated capacity and intent is wasteful and undercuts local accountability. Differential starting points (asymmetric decentralisation) can be constructive, such that these LRG variations are recognised in the reform process. Some reforms could even be negotiated with LRGs, placing some onus on them to observe steps they agreed to. Such an approach may also help ensure that LRGs will try to prepare for more responsibility and also improve the confidence of other stakeholders.

A further issue is that individual elements of LRG governance should ideally be linked to recognise the interdependencies outlined above, even if initially in a limited way. A fragmented reform approach targeting only limited aspects of the system may sometimes be effective, but it can also result in reforms that appear consistent with accepted principles and good practice but cannot independently create or sustain desired results.

Second, there is value in constructing both positive and negative incentives (rewards and penalties) for central and local and regional actors to meet agreed measures. Where multiple actors (e.g. ministries that must take actions to empower or support LRGs and/or international development partners who provide assistance), are involved, some institutional mechanism to oversee, support and 
enforce implementation could help to motivate all actors to meet their obligations. Developing such mechanisms is not easy, but efforts in this direction can raise awareness and help to improve compliance.

Various types of incentives may encourage LRG adoption of reforms and improve performance. These include: enforceable accountability mechanisms, such as central government contracts with LRGs (e.g. Rwanda); financial incentives to adopt reforms and meet targets (e.g. Bangladesh and Uganda), such as compliance or performance-based grants; and tournament approaches, such as contests or review processes that recognise improved service delivery, revenue generation or other LRG achievements (e.g. Australia and the Philippines).

Third, enhancing capacity building and technical assistance are widely acknowledged as critical for implementing LRG reform. These functions, however, are often standardised and mechanical. Although lessening, there has been a persistent predisposition to use traditional supply-driven classroom training and not enough 'on the job' training to enhance the development, application and retention of relevant skills. Even more fundamentally, without civil service systems that adequately compensate staff and provide meaningful career progression, those with enhanced capacity may move to other jobs.

There has also been an enduring bias on developing technical skills, which are obviously important, but governance capacity is also needed for sustainable reform. LRGs need to learn how to work more effectively with higher-level governments, their peers and their constituents, and elected and appointed LRG officials must also work effectively together. To some extent such needs are recognised in the push to improve accountability in multi-stakeholder environments, but consensus may be more on paper than in practice, and governance capacity may continue to be pursued in superficial and piecemeal ways.

Finally, the overall strategy needs to be consolidated. The trajectory of reform, which as noted above can have different starting points and paces, should ideally incorporate incentives and be directly linked to efforts to build capacity and improve performance over time. Technical reforms can be rolled out in a way that ties capacity development to specific functions that will be undertaken during a particular period. Reforms could progressively proceed based on well-defined criteria that make it clear what a LRG must do before being empowered with additional responsibilities or resources.

Such an approach can be challenging and may risk becoming overly bureaucratic, and in cases with more advanced systems in place and generally stronger capacity it will not be necessary. More thinking and effort in this direction, however, can often be productive, and it may reduce arbitrary or politicised decisions about moving on to next steps and limit stalling of LRG empowerment processes which is often experienced, especially in low-income countries. 
An implementation strategy will also be required for actions LRGs can take more independently of the national government. Even capable LRGs will often need to act strategically in adopting reforms that, for example, require major increases in taxes paid by local residents. One approach might be to tie revenue increases to specific benefits. If moving to full property valuation is intended and current valuations are low, assessment ratios could be phased in and tied to service improvements for local businesses and residents. Similarly, new user charges could move gradually towards cost recovery to avoid undesirable inequities, reductions in basic service use, adverse administrative impacts, political resistance, etc. New systems and procedures could also be tested through pilot initiatives, allowing experimentation and modification before wider adoption.

\section{Linking fiscal decentralisation reforms to the SDGs}

As emphasised throughout this article, fiscal decentralisation reforms have been pursued for decades, often with underwhelming or mixed results. ${ }^{10}$ The emergence and prominence of the SDGs present an opportunity to weigh the implications of the SDGs for the strategic pursuit of decentralisation reforms. Assessing how to localise and implement the SDGs can also provide insights into how to prioritise and sequence decentralisation reforms, both fiscal and beyond. Pursuing reforms in this way may help to get traction on essential fiscal decentralisation reforms that have not taken root in previous incarnations.

Although there is a common set of SDGs, each country's particular challenges with respect to those goals, their relative priorities, and the potential for the current LRG system to help attain them varies considerably. Thus, the design and implementation of any reform programme needs to be country specific, considering context, politics, capacity and other factors noted above. National governments are at different stages of aligning their national development plans to the SDGs, but there will often be room for improving efforts to contextualise and pragmatically frame their SDG strategy.

Differences across countries also implies that a set of contextualised - rather than standardised institutions and processes are needed to pursue the SDGs and shape the role of LRGs in doing so. Each country will need to develop an approach to connect the SDGs to any relevant reshaping of intergovernmental structures, functions, resources and relations. Even with the SDGs as a focus, the process can determine constructive LRG reform strategies and support mechanisms. Although individual countries should drive the approach to the SDGs, many may need external support, especially in low- and middle-income countries, and all could benefit from a means to exchange country experiences.

If LRGs are to be key players in achieving the SDGs, several critical steps must generally be taken. These measures must, of course, be properly tailored to the contexts and needs of specific countries

${ }^{10}$ Elaboration of the points outlined here is provided in UCLG (2015) and Smoke and Nixon (2016). 
and appropriately supported by the international community as requested by countries that need and desire assistance:

- First, LRGs will often need to be more robustly empowered to act not only more autonomously, but also as players in a multi-actor team. The degree of empowerment required will necessarily vary across and perhaps within countries.

- Second, LRGs need sufficient resources to carry out their functions. As discussed above, LRG revenue sources should be developed in an integrated way that ensures better operation of the overall system. Development finance is a priority for many SDGs, but it is dependent on overall fiscal capacity.

- Third, LRGs need increased incentives to operate transparently and in an accountable manner. This means getting an appropriate balance between upward and downward accountability, which can evolve over time as LRGs improve capacity and results. Good information and monitoring are essential.

- Fourth, LRGs need capacity to function effectively and to act developmentally. Capacity needs will vary - both in terms of general LRG requirements and the demands of specific SDGs.

Another basic consideration is what type of strategic process is needed to move forward. Several elements would need to be considered:

- First, the starting point is to document the current situation in a particular country, including intergovernmental relations and contextual conditions that could support or hinder more effective LRGs. This is, of course, a very large area of inquiry, but it is important to have a general understanding of the strengths and weaknesses of the intergovernmental system as per the discussion above.

- Second, SDG deficits should be identified. Some of these deficits would be related to the unmet potential role of LRGs in more specific SDGs, such as particular services, conflict management, or infrastructure, while others relate to more holistic issues such as economic growth, inequality and resilience.

- Third, based on previous assessments, it will be necessary to determine priority reforms and articulate pragmatic strategies for enhancing LRG systems and practices. The strategy should identify entry points, sequencing, and pace, as well as the types of incentives, support, and capacity building that might be required.

- Fourth, it is essential to develop institutions and processes for monitoring the progression of reforms and their relationship to the SDGs. Some standard benchmarks may be useful, but there is also room for negotiating some of them with LRGs. The results can be used to inform 
and enable adjustments to the reform objectives and the strategy itself as lessons are learned from experience.

Given the breadth and complexity of the SDGs and prominent differences in the LRG context and needs across countries, there is no single best approach to how LRGs can support the SDGs. Moreover, there is no single best answer to the question of which intergovernmental system reforms have the greatest potential to improve the ability of LRGs to promote sustainable development.

Commonwealth members, like all countries, face the pressing and consequential challenge of making progress on this front. Creating and applying better diagnostics can help policymakers and practitioners to better understand current conditions and needs. Developing dynamic processes that make use of improved information and include relevant stakeholders in a meaningful way can support strategic advances in meeting the SDGs with greater contributions from more empowered, capable and motivated LRGs.

\section{Declaration of conflicting interest}

The author declared no potential conflicts of interest with respect to the research, authorship, and/or publication of this article.

\section{Funding}

This paper was commissioned by the Commonwealth Local Government Forum with the assistance of the European Union and PLATFORMA, and an earlier version was produced as the background paper to the 2017 Commonwealth Local Government Conference, held in Valletta, Malta Nov 21-24.

\section{References}

AFD and UNDP. (2016) Financing the SDGs in the least developed countries: Diversifying the financing toolbox and managing vulnerability. Paris and New York: Agence Française de Développement and United Nations Development Programme.

Agrawal, A. and Ribot, J. (2012) Assessing the effectiveness of democratic accountability mechanisms in local governance. Washington, DC: USAID.

Bahl, R. and Bird, R. (2008) Subnational taxes in developing countries: The way forward. Public Budgeting and Finance, 28 (4), 1-25. https://doi.org/10.1111/j.1540-5850.2008.00914.X

Bahl, R., Linn, J. and Wetzel, D. (eds.) (2013) Financing metropolitan governments in developing countries. Cambridge, MA: Lincoln Institute of Land Policy.

Bird, R. and Smart, M. (2002) Intergovernmental fiscal transfers: International lessons for developing countries. World Development, 30 (6), 899-912. https://doi.org/10.1016/s0305-750x(02)00016-5

Boex, J. and Yilmaz, S. (2010) An analytical framework for assessing democratic local governance and the local public sector. Washington, DC: The Urban Institute.

Brinkerhoff, D. and Brinkerhoff, J. (2011) Public-private partnerships: Perspectives on purposes, publicness and good governance. Public Administration and Development, 31 (1), 2-14. https://doi.org/10.1002/pad.584

Commonwealth Local Government Forum. (2007) The Aberdeen agenda: Commonwealth principles on good practice for local democracy and good governance. London: CLGF. 
Commonwealth Local Government Forum. (2013) Developmental local government: Putting local government at the heart of development. London: CLGF.

Commonwealth Local Government Forum. (2015) Commonwealth Local Government handbook 2015-16. London: CLGF.

Connerly, E., Eaton, K. and Smoke, P. (eds.) (2010) Making decentralization work: Democracy, development and security. Boulder, CO: Lynne Rienner Publishers. https://doi.org/10.1017/s1537592711003689

Eaton, K., Kaiser, K. and Smoke, P. (2011) The political economy of decentralization reform: Implications for aid effectiveness. Washington, DC: The World Bank. https://doi.org/10.1596/978-0-8213-8840-2

European Commission. (2016) Supporting decentralisation, local governance and local development through a territorial approach. Brussels: European Commission, Directorate General for International Cooperation and Development.

Faguet, J-P. (2014) Decentralisation and governance. World Development, 53 (1), 2-13. https://doi.org/10.1016/j.worlddev.2013.01.002

FMDV. (2015) The potential catalytic role of subnational pooled financing mechanisms. Paris: Fonds Mondial de Développement des Villes/Global Fund for Cities Development.

Frank, J. and Martinez Vazquez, J. (2016) Decentralisation and infrastructure in the global economy. Cheltenham: Edward Elgar.

GIZ. (2014) The future of multilateral concessional finance. Bonn: GIZ.

Greene, S. and. Meixell, B. (2017) Hacking the sustainable development goals. Washington, DC: Urban Institute.

Ingram, G. and Hong, Y. (2012) Value capture and land policies. Cambridge, MA: Lincoln Institute of Land Policy.

Ingram, G., Liu, Z. and Brandt, K. (2013) Metropolitan infrastructure and capital finance. In: Bahl, R., Linn, J. and Wetzel, D. (eds.) Financing metropolitan governments in developing countries. Cambridge, MA: Lincoln Institute of Land Policy.

Kehew, R., Matsukawa, T. and Petersen, J. (2005) Local financing for sub-sovereign infrastructure in developing countries. Washington, DC: World Bank.

Local Development International. (2013) The role of decentralisation/devolution in improving development outcomes at the local level: A review of the literature and selected cases. London: UK Department for International Development.

Marin, P. (2009) Public private partnerships for urban water. Washington, DC: The World Bank. https://doi.org/10.1596/978-0-8213-7956-1

Martinez-Vazquez, J. (2013) Local non-property revenues. In: Bahl, R., Linn, J. and Wetzel, D. (eds.) Financing metropolitan governments in developing countries (pp. 183-211). Cambridge, MA: Lincoln Institute of Land Policy.

Martinez-Vazquez, J. and Timofeev, A. (2012) Propensity to invest and the additionality of capital transfers: A country panel perspective. Atlanta. GA: International Center for Public Policy, Andrew Young School of Policy Studies, Georgia State University. https://doi.org/10.2139/ssrn.2186131

Matsukawa, T. and Habeck, O. (2007) Recent trends in risk mitigation instruments for infrastructure finance. Washington, DC: The World Bank.

McCluskey, W. and Franzen, R. (2013) Property taxation in metropolitan cities. In: Bahl, R., Linn, J. and Wetzel, D. (eds.) Financing metropolitan governments in developing countries (pp. 159-181). Cambridge, MA: Lincoln Institute of Land Policy.

McGranahan, G. and Satterthwaite, D. (2014) Urbanization concepts and trends. IIED Working Paper. London: International Institute for Environment and Development.

OECD and UCLG (2016) Subnational governments around the world: Structure and finance. Paris and Barcelona: Organization for Economic Cooperation and Development and United Cities and Local Governments. 
Romeo, L. (2011) Decentralizing for development. The developmental potential of local autonomy and the limits of politics driven decentralization reforms. ICLD Working Paper 11.

Shah, A. (2013) Grant financing of metropolitan areas. In: Bahl, R., Linn, J. and Wetzel, D. (eds) Financing metropolitan governments in developing countries (pp. 213-242). Cambridge, MA: Lincoln Institute of Land Policy.

Slack, E. (2015) Innovative governance approaches in metropolitan areas of developing countries. In: The challenge of local government financing in developing countries (pp. 61-82). Nairobi: UN-Habitat,

Smoke, P. (2013) Cities in the national institutional and fiscal structure. In: Bahl, R., Linn, J. and Wetzel, D. (eds.) Financing metropolitan governments in developing countries (pp. 57-84). Cambridge, MA: Lincoln Institute of Land Policy.

Smoke, P. (2015a) Rethinking decentralization: Assessing challenges to a popular public sector reform. Public Administration and Development. 35 (2), 97-112. https://doi.org/10.1002/pad.1703

Smoke, P. (2015b) Managing public sector decentralization in developing countries: Moving beyond conventional recipes. Public Administration and Development. 35 (4), 250-262. https://doi.org/10.1002/pad.1736

Smoke, P. and Nixon, H. (2016) Sharing responsibilities and resources among levels of government: Localizing the sustainable development goals. New York: UN Department for Economic and Social Affairs, Division of Public Administration and Development Management.

Suzuki, H., Murakami, J., Hong Y. and Tamayose. B. (2015) Financing transit oriented development with land values. Washington, DC: The World Bank. https://doi.org/10.1596/978-1-4648-0149-5

UCLG. (2010) Financing local government: The challenges of the $21^{\text {st }}$ century. Second Global Report on Decentralization and Local Governance. Barcelona: United Cities and Local Governments.

UCLG. (2014) Access to basic services. Third Global Report on Decentralization and Local Governance. Barcelona: United Cities and Local Governments.

UCLG. (2015) Financing urban and local development: The missing link in sustainable development finance. Barcelona: Global Task Force of Local and Regional Governments, United Cities and Local Governments.

UN General Assembly. (2014) The road to dignity by 2030: Ending poverty, transforming all lives and protecting the planet. Synthesis Report of the Secretary General on the Post-2015 Sustainable Development Agenda. New York: United Nations General Assembly.

UNDESA Division for Sustainable Development. (2015) Transforming our world: The 2030 agenda for sustainable development. New York, NY: UN Department for Economic and Social Affairs, Division for Sustainable Development.

UNDESA Financing for Development Office. (2015) Addis Ababa action agenda of the third international conference on financing for development. New York: UN Department for Economic and Social Affairs, Financing for Development Office.

UNDESA. (2017) World urbanization prospects. New York, NY: UN Department for Economic and Social Affairs.

UNDESA and UNCDF. (2017) Financing sustainable urban development in the least developed countries. New York: UN Department for Economic and Social Affairs Financing for Development Office and UN Capital Development Fund.

UN-Habitat. (2015) The challenge of local government financing in developing countries. Nairobi: UN-Habitat.

UN-Habitat. (2016) World cities report 2016: Urbanization and development; emerging futures. Nairobi: UNHabitat. https://doi.org/10.18356/d201a997-en

UN-Habitat Habitat III Secretariat. (2016) The new urban agenda. Nairobi: UN-Habitat. https://doi.org/10.18356/4665f6fb-en

UN-Habitat and IDB. (2017) Sustainable municipal finance for development: Policies and cases of subnational, municipal and metropolitan finance for the new urban agenda. Nairobi and Washington, DC: UN HABITAT and Inter-American Development Bank. 
World Economic Forum. (2014) Accelerating infrastructure delivery: New evidence from international financial institutions. Geneva: World Economic Forum.

Yilmaz, S., Beris, Y. and Serrano, R. (2010) Linking local government discretion and accountability in decentralization. Development Policy Review, 28 (3), 259-293. https://doi.org/10.1111/j.14677679.2010.00484.x 